\title{
Effect of exogenous butyrate on the gastrointestinal tract of sheep. II. Hydrolytic activity in the rumen and structure and function of the small intestine ${ }^{1}$
}

\author{
Paweł Górka, ${ }^{*, 2,}$ Bogdan Śliwiński, ${ }^{\dagger}$ Jadwiga Flaga, ${ }^{*}$ Jarosław Olszewski, \\ Paulina Nawrocka, * Klaudyna Sobkowiak, * Renata Miltko," Michał M. Godlewski, \\ Romuald Zabielski, ${ }^{\circledR}$ and Zygmunt M. Kowalski*
}

*Department of Animal Nutrition and Dietetics, University of Agriculture in Krakow, al. Mickiewicza 24/28, 30-059 Krakow, Poland; 'Department of Animal Nutrition and Feed Science, National Research Institute of Animal Production, ul. Krakowska 1, 32-083 Balice, Poland; *Department of Physiological Sciences, Faculty of Veterinary Medicine, Warsaw University of Life Sciences, ul. Nowoursynowska 159, 02-766 Warszawa, Poland;

\|The Kielanowski Institute of Animal Physiology and Nutrition, Polish Academy of Sciences, ul. Instytucka

3, 05-110 Jabłonna, Poland; and ${ }^{\$}$ Department of Large Animal Diseases with Clinic, Faculty of Veterinary

Medicine, Warsaw University of Life Sciences, ul. Nowoursynowska 100, 02-797 Warszawa, Poland

\begin{abstract}
The aim of this study was to determine the effect of exogenous butyrate on the activity of carbohydrate-digesting enzymes in the reticuloruminal digesta and structure and selected functions of the small intestine in sheep. Eighteen rams $(30.8 \pm 2.1 \mathrm{~kg} ; 12$ to 15 mo of age) were fed for $14 \mathrm{~d}$ a diet without (CTRL) or with sodium butyrate (BUT; $36 \mathrm{~g} / \mathrm{kg}$ of offered DM). Butyrate concentration in the reticuloruminal fluid and proximal small intestinal digesta was greater for BUT compared with CTRL $(P \leq 0.05)$. Amylolytic activity was greater, whereas cellulolytic and xylanolytic activity in the reticuloruminal digesta was less for BUT compared with CTRL $(P \leq$ 0.04). Relative to BW, small intestinal tissue mass and small intestine length did not differ between treatments $(P \geq 0.15)$; however, absolute length of the small intestine was greater for BUT compared with CTRL $(P=0.04)$. In the duodenum, crypt
\end{abstract}

depth tended $(P=0.10)$ to be greater, whereas in the ileum, crypt depth and muscularis thickness tended $(P=0.10)$ to be less for BUT compared with CTRL. Mitosis-to-apoptosis ratio in the proximal jejunum was greater for CTRL compared with BUT $(P=0.02)$. Expression of G-protein-coupled receptor $43 \mathrm{mRNA}$ in the duodenal epithelium was greater for BUT compared with CTRL $(P<0.01)$. On the other hand, peptide transporter 1 mRNA expression in the distal sections of the small intestine, as well as activity of aminopeptidase A and dipeptidylpeptidase IV, were greater for CTRL $(P \leq 0.05)$. In summary, exogenous butyrate supplementation in feed affects hydrolytic activity in the rumen, and increased butyrate flow out of the reticulorumen affects both proximal and distal sections of the small intestine in sheep.

Key words: digestive enzymes, enzyme activity, gastrointestinal tract, nutrient absorption, ruminant

(C) The Author $(s)$ 2018. Published by Oxford University Press on behalf of the American Society of Animal Science. All rights reserved. For permissions, please e-mail: journals.permissions@oup.com.

J. Anim. Sci. 2018.96:5325-5335 doi: 10.1093/jas/sky368

\footnotetext{
${ }^{1}$ This study was supported by the National Science Centre (Poland) based on decision No. DEC-2013/11/B/ NZ9/01938 and the Statutory Research Fund of The Kielanowski Institute of Animal Physiology and Nutrition, Polish Academy of Sciences. The authors would like to thank Barbara Dudzik and Kazimierz Strumiński for their technical support and the Department of Animal Nutrition and
}

Dietetics employees for their help with sample collection. The assistance of Dr. Dorota Wojtysiak with the tissue sampling protocol preparation and Dr. Jarosław Wieczorek for the veterinary care of the animals is also greatly acknowledged.

${ }^{2}$ Corresponding author: p.gorka@ur.krakow.pl

Received March 26, 2018.

Accepted June 3, 2018. 


\section{INTRODUCTION}

Of the three most important short-chain fatty acids (SCFA) released in the rumen by microbes (acetate, propionate, and butyrate), butyrate is the least abundant but its concentration and production in the rumen is the most dynamic (Ploger et al., 2012). Its molar proportion in total SCFA accounts for about $10 \%$ but may increase up to $20 \%$ when rapidly fermentable carbohydrates (e.g., starch, sugar) are provided in the feed (DeFrain et al., 2004; Chibisa et al., 2015). An increase in ruminal butyrate is known to stimulate rumen papillae growth (Malhi et al., 2013; Kowalski et al., 2015), expression of genes mediating SCFA absorption from the rumen (Malhi et al., 2013; Dengler et al., 2014), and blood flow through the ruminal epithelium (Storm et al., 2011). Therefore, nutritional strategies promoting butyrate production in the rumen or its dietary supplementation are commonly used to enhance ruminal epithelium functions and, in turn, performance of animals (Górka et al., 2011a; Chibisa et al., 2015; Kowalski et al., 2015). However, direct infusion of butyrate into the reticulorumen resulted in greater butyrate flow into the duodenum (Górka et al., $2017 b$ ), and butyrate infusion into the abomasum affected the expression of numerous genes in the duodenal epithelium in sheep (Foote et al., 2017). As a result, increased ruminal butyrate may affect not only the rumen, but also lower parts of the gastrointestinal tract (GIT), including the small intestine.

We hypothesized that besides affecting the rumen, increased ruminal butyrate will affect both the structure and function of the small intestine due to increased butyrate flow into the duodenum. In the present study, sodium butyrate was supplemented in the diet in order to increase ruminal butyrate in sheep. The specific aims of this study were to determine the effect of exogenous butyrate on the small intestinal tissue mass, small intestinal epithelium structure, mitotic and apoptotic indexes of the intestinal epithelium, activity of brush border enzymes, and mRNA expression of glucose transporters (sodium/glucose cotransporter 1 and facilitative glucose transporter 2), peptide transporter (peptide transporter 1), SCFA transporters (monocarboxylate transporter 1, 2, and 4), and SCFA receptors (G-protein-coupled receptor 41 and 43) in the intestinal epithelium of sheep. The aforementioned transporters of nutrients and SCFA receptors were used as markers of butyrate impact on small intestine function in the present study. Furthermore, the impact of exogenous butyrate on the activity of carbohydrate-digesting enzymes in the reticuloruminal digesta was investigated.

\section{MATERIALS AND METHODS}

\section{Animals, Experimental Design, and Treatments}

The experimental protocol was reviewed and approved by the local ethics committee (Krakow, Poland) before study initiation (protocol No. 190/2015). The animals used for this study and the experimental procedures have been described elsewhere (Górka et al., 2018). Briefly, 18 Wrzosówka rams $(30.8 \pm 2.1 \mathrm{~kg} ; 12$ to 15 mo of age) were allocated to the study in four blocks of $6,4,4$, and 4 rams. Within each block, the rams were paired by BW and, within pairs, randomly allocated to 1 of 2 treatments ( 9 rams/treatment) and fed a diet without (CTRL) or with sodium butyrate (BUT). Sodium butyrate was supplemented in the feed at the rate of $36 \mathrm{~g} / \mathrm{kg}$ of offered DM that corresponded with the doses of butyrate used in previous studies in cattle (Huhtanen et al., 1993) and sheep (Wilson et al., 2012; Wiese et al., 2013; Górka et al., 2017b). The diet consisted of chopped meadow hay $(65 \%)$, concentrates $(19.5 \%)$, and ensiled ground high-moisture corn grain (15.5\%, DM basis). Dry matter intake was limited to $2.75 \%$ of $\mathrm{BW}$. Throughout the whole study period, the animals were kept and fed individually. The feeds were offered in 2 equal meals at 0700 and 1500. For BUT, the sodium butyrate was mixed with concentrates and ensiled high-moisture corn grain just before feed allocation. A mixture of concentrates and high-moistrue corn grain with or without sodium butyrate was fed $30 \mathrm{~min}$ prior to hay allocation in order to assure complete intake of the butyrate.

\section{Sample Collection}

After $14 \mathrm{~d}, 3 \mathrm{~h}$ after morning feeding, the rams were killed by captive bolt stunning and exsanguination. Immediately after killing, the GIT was removed and the reticulorumen, omasum, abomasum, and small intestine were separated. The reticuloruminal digesta was emptied into a designated container. The digesta from the proximal small intestine (first $1 \mathrm{~m}$ length of the small intestine) was emptied into a designated container right after this section was separated from the mesentery, and then the small intestine was gently separated from the mesentery and divided into the duodenum (with the end determined by the ligament of Treitz), the jejunum (with the end determined based on the ileocecal fold), and the ileum (with the end at the ileocecal junction; Górka et al., 2017a), emptied from the digesta, and measured and weighed individually. 
Epithelial samples from the midpoint of the duodenum, proximal jejunum (at $25 \%$ of total length), middle jejunum (at $50 \%$ of total length), distal jejunum (at $75 \%$ of total length), and midpoint of the ileum were scraped using a microscope slide and stored in RNAlater (Ambion, Austin, TX, USA; 150 to $200 \mathrm{mg}$ ) and frozen ( 2 to $3 \mathrm{~g}$ ) in liquid nitrogen and subsequently stored at $-80{ }^{\circ} \mathrm{C}$. Prior to tissue collection, the intestine sections ( $\approx 30 \mathrm{~cm}$ length) were cut open, rinsed with ice-cold PBS and blotted dry. Cross-sections of the small intestine tissues ( $\approx 5 \mathrm{~cm}$ length) from the corresponding locations of the epithelial scrapings were gently rinsed with PBS and stored in 10\% neutral buffered formalin solution (Sigma-Aldrich, St. Louis, MO, USA) for $24 \mathrm{~h}$ and then in $70 \%$ ethanol (POCH, Gliwice, Poland).

The reticuloruminal digesta was thoroughly mixed and $50 \mathrm{~g}$ was collected, placed on dry ice, frozen, and subsequently stored at $-80^{\circ} \mathrm{C}$. Proximal small intestinal digesta $\mathrm{pH}$ was measured $(\mathrm{pH}$ meter N517, Meratronic, Warszawa, Poland) and $5 \mathrm{~mL}$ of whole digesta was collected and preserved with $1 \mathrm{~mL}$ of metaphosphoric acid (25\% wt/vol) and stored frozen $\left(-20^{\circ} \mathrm{C}\right)$ for SCFA analysis.

\section{Sample Analyses}

Short-chain fatty acids concentration in duodenal digesta was determined by gas chromatography (3400 CX; Varian Star, Palo Alto, CA, USA) equipped with a flame ionization detector using a DB-FFAP column $(30 \mathrm{~m} \times 0.5 \mathrm{~mm}$; J\&W Scientific, Folsom, CA, USA), as described previously by Górka et al. (2017b).

Tissue samples preserved in formalin and stored in ethanol were dehydrated in a graded ethanol series, cleared in xylene, and embedded in paraffin. Prior to embedding, the tissue samples were divided into four $0.5 \mathrm{~cm}$ thick pieces and each piece was embedded in a separate paraffin block. Six-micrometer thick sections were cut from each paraffin block and stained with hematoxylin and eosin for morphometry measurements or determination of mitotic and apoptotic indices, as described in the latter part of the paper. For the purposes of morphometric measurements, 3 to 4 sections were cut from each paraffin block, with each section cut $200 \mu \mathrm{m}$ apart from the previous one. This resulted in 12 to 16 different areas of view per sample. Villus length, crypt depth, mucosa, and muscularis thickness were measured as described previously by Górka et al. (2011b) using a light microscope (10× objective lens and $16 \times$ ocular; Zeiss Axio Imager M2, Zeiss, Göttingen, Germany) captured with a Canon PowerShot G10 video camera (Canon, Tokyo, Japan) and AxioVision software (Zeiss, Göttingen, Germany), targeting 30 measurements for each parameter and animal.

Expression of Ki-67 and active caspase-3 was determined in the proximal jejunum and ileum epithelium by scanning cytometry (Godlewski et al., 2009; Górka et al., 2011b). Antigens were exposed through citrate buffer heating $(\mathrm{pH}=6.0)$ for $5 \mathrm{~min}$ and then cooled for at least $20 \mathrm{~min}$ at room temperature. After washing with PBS buffer $(\mathrm{pH}=7.2)$, the tissue sections were covered for $45 \mathrm{~min}$ with bovine serum albumin (Sigma-Aldrich) to block nonspecific antibody binding. Individual slides were then incubated with antibodies: anti-Ki67 (mouse polyclonal anti-human Ki-67; 612472:FITC; BD Pharmingen, San Diego, CA; incubation for $180 \mathrm{~min}$ at room temperature; dilution 1:200), or anti-Active Caspase-3 (rabbit polyclonal anti-human active caspase-3; CPP32:FITC; BD Pharmingen; incubation for $180 \mathrm{~min}$ at room temperature; dilution $1: 150)$. Finally, the nuclei were counterstained with HOECHST 33342 (Sigma-Aldrich). Afterwards, the samples were rinsed in PBS and the slides were mounted with fluoromount (Sigma-Aldrich) under coverslips. For quantitative evaluation of Ki-67 positive or active-caspase- 3 positive cell indexes, process-related fluorescence was analyzed for all tissue samples under the $\mathrm{SCAN}^{\wedge} \mathrm{R}$ scanning cytometer (Olympus, Warszawa, Poland). The cells were identified using Hoechst 33342 fluorescence associated with nuclei. Cell-related fluorescence was measured within an outline of +10 pixels around the contour of the nuclei. A standard mathematical protocol for tissues in the scanning cytometry, based on the average distance between nuclei with and without overlap between neighboring cells, was used to eliminate cell aggregates and debris. Following the analyses, the results were presented as the indexes of cells positive for the Ki-67 and active caspase- 3 fluorescence. For the Ki-67 index only, the area of intestinal crypts was evaluated, whereas active caspase- 3 index was evaluated in the whole depth of the intestine mucosa.

Carbohydrate-digesting enzymes in the reticuloruminal digesta, including amylolytic, cellulolytic, xylanolytic, inulinolytic, and pectinolytic activity, were analyzed as previously described (Miltko et al., 2016). In brief, the samples of reticuloruminal digesta were incubated with $\mathrm{CCl}_{4}$ and $1 \%$ phosphate buffer $(\mathrm{pH}$ 6.0) in the presence of lysozyme solution. The extract was centrifuged and the supernatant obtained was collected and used as an enzymatic fraction. The reaction mixture 
consisted of $0.4 \mathrm{~mL}$ of substrate, $0.4 \mathrm{~mL}$ of enzymatic fraction, and $0.2 \mathrm{~mL}$ of phosphate buffer $(\mathrm{pH}$ 6.0). The mixture was incubated for $1 \mathrm{~h}$ at $40{ }^{\circ} \mathrm{C}$, and the reaction was stopped by the addition of dinitrosalicylic acid reagent (Miller et al., 1960) and heating at $100{ }^{\circ} \mathrm{C}$ for $5 \mathrm{~min}$. A $2 \%$ solutions of starch, carboxymethyl cellulose, xylan (all from Sigma-Aldrich), and inulin (Orafti HPX; BENEO $\mathrm{GmbH}$, Mannheim, Germany), as well as $0.2 \%$ solution of pectin (Sigma-Aldrich) were used as substrates. The enzymatic fraction without substrate and the substrate without the enzymatic fraction were always concomitantly incubated as controls. The concentration of the reducing sugars released during incubation of the enzymatic fraction with substrates was quantified spectrophotometrically at $560 \mathrm{~nm}$ (HACH LANGE DR 6000 UV VIS Spectrophotometer; Hach Company, Loveland, CO, USA). The DM of the reticuloruminal digesta was determined by drying samples at $105^{\circ} \mathrm{C}$ for $48 \mathrm{~h}$. The results are presented as enzymatic units (U) normalized for reticuloruminal digesta DM. One enzymatic unit represents $1 \mu \mathrm{mol}$ of monosaccharide (glucose, xylose, fructose, and galacturonic acid for amylolytic and cellulolytic as well as xylanolytic, inulinolytic, and pectinolytic activity, respectively) released/min of reaction. The intra and interassay $\mathrm{CV}$ were $<2 \%$ and $<6 \%$, respectively.

Total protein content and activity of the selected brush border enzymes in the intestinal epithelial scrapings were determined as described previously (Górka et al., 2017a). In brief, $1 \mathrm{~g}$ of epithelial scrapings was homogenized with $5 \mathrm{~mL}$ of distilled water and centrifuged for $5 \mathrm{~min}$ at $1000 \times g$ at $4{ }^{\circ} \mathrm{C}$. Lactase and maltase activities were determined according to Dahlqvist (1984). Aminopeptidase A, aminopeptidase N, and dipeptidylpeptidase IV activities were determined using L-glutamyl- $p$-nitroanilide, L-leucyl- $p$-nitoanilide, and L-glycyl-p-nitroanilide (Bachem, Budendorf, Sweden) as substrates, respectively (Maroux et al., 1973; Nagatsu et al., 1976). Each sample was run at least in duplicate. The total protein content in supernatant was determined with modified Lowry method according to Hartree (1972), and bovine serum albumin was used as a standard. The interand intra-assay $\mathrm{CV}$ for total protein concentration, lactase, and maltase activities were $<3 \%$, whereas inter- and intra-assay $\mathrm{CV}$ for aminopeptidase A, aminopeptidase $\mathrm{N}$, and dipeptidylpeptidase IV activities were $<10 \%$ and $<7 \%$, respectively. Enzymatic activity was presented as enzymatic units normalized for total protein content in the supernatant $\left(\mathrm{U} \times 10^{-3} / \mathrm{g}\right.$ protein) with one enzymatic unit expressing $1 \mu \mathrm{mol}$ of glucose or $p$-nitroanilide released $/ \mathrm{min}$ of reaction at $37^{\circ} \mathrm{C}$.

Total RNA was isolated from tissue samples stored in RNAlater according to the method described by Chomczyński and Sacchi (1987), and subsequently subjected to reverse transcription reaction. Validation of the quality and quantity of RNA as well as reverse transcription reaction procedure were done as described previously (Górka et al., 2017b). The concentration and integrity of RNA was estimated spectrophotometrically using NanoDrop (Thermo Fisher Scientific, Waltham, MA, USA) and verified electrophoretically in the agarose gel. Only samples with the optical density (OD) absorption ratio $\mathrm{OD}_{260 \mathrm{~nm}} / \mathrm{OD}_{280 \mathrm{~nm}}$ between 1.8 and 2.0 and without signs of degradation were used for further analysis. The obtained cDNA was stored at $-20{ }^{\circ} \mathrm{C}$ until analyzed for expression of sodium-dependent glucose cotransporter 1 (SGLT1), glucose transporter 2 (GLUT2), peptide transporter 1 (PepT1), monocarboxylate transporter 1 (MCT1), monocarboxylate transporter 2 (MCT2), monocarboxylate transporter 4 (MCT4), G-proteincoupled receptor 41 (GPR41), G-protein-coupled receptor 43 (GPR43), and 3 reference genes [glyceraldehyde-3-phosphate dehydrogenase (GAPDH), $\mathrm{Na} / \mathrm{K}$-ATPase, and $\beta$-actin (ACTB)]. Gene expression was determined in duplicate, and each reaction was performed as previously described (Górka et al., 2017b) using specific primers (Supplementary Table S1). NormFinder was used to determine the most optimal reference gene(s) (Andersen et al., 2004), and geometric mean of GAPDH and Na/KATPase was chosen for the normalization of the target genes. The interassay coefficient of variance for internal control was $0.44 \pm 0.31 \%$. To ensure correct result of analysis, the product of reaction for each primer was sequenced and the homology between the target and product sequence was verified. Relative expression of the investigated genes was presented as $\Delta \mathrm{C}_{\mathrm{T}}$, where $\Delta \mathrm{C}_{\mathrm{T}}=$ threshold cycle $\left(\mathrm{C}_{\mathrm{T}}\right)$ for target gene $-\mathrm{C}_{\mathrm{T}}$ for reference. Therefore, a higher $\Delta \mathrm{C}_{\mathrm{T}}$ value represented lower mRNA expression and vice versa.

\section{Statistical Analysis}

Data were analyzed using the MIXED procedure of SAS (version 9.2; Cary, NC, USA). The model included the fixed effect of treatment. Block and pair of animals within a block were included in the model as random effects. The results are presented as least square means and their 
corresponding standard errors. Significance was declared at $P \leq 0.05$ and tendencies were discussed when $0.05<P \leq 0.10$.

\section{RESULTS}

Data on feed composition, feed intake, and BW of animals as well as impact of exogenous butyrate on the reticulorumen, omasum, and abomasum are presented in the companion paper (Górka et al., 2018). As planned, DMI did not differ between treatments ( 862 vs. $864 \mathrm{~g} / \mathrm{d}$ for CTRL and BUT, respectively, $P \geq 0.61$ ), whereas butyrate concentration in the reticuloruminal (20.7 vs. $11.7 \mathrm{mmol} / \mathrm{L})$ and abomasal digesta (2.03 vs. $1.31 \mathrm{mmol} / \mathrm{L})$ was greater for BUT compared with CTRL $(P \leq 0.01)$.

Butyrate concentration in the digesta of the proximal small intestine was greater $(P=0.05)$ while valerate and isobutyrate tended $(P \leq 0.09)$ to be greater for BUT compared with CTRL (Table 1). The length of the whole small intestine and jejunum was greater $(P \leq 0.05)$, whereas tissue mass for the whole small intestine and jejunum tended $(P \leq$ $0.10)$ to be greater for BUT compared with CTRL. However, when expressed relative to the BW (g or $\mathrm{cm} / \mathrm{kg} \mathrm{BW}$ ), neither the length and mass of the small intestine nor its sections differed between treatments $(P \geq 0.15$; Table 2$)$. In the duodenum, crypt depth tended $(P=0.10)$ to be greater, whereas in the ileum, crypt depth and muscularis thickness tended $(P=0.10)$ to be less for BUT compared with CTRL (Table 3). Mitosis-to-apoptosis ratio in the duodenal epithelium was greater for CTRL compared with BUT $(P=0.02$; Table 4$)$, mostly due to the tendency to greater apoptotic index for the latter treatment $(P=0.10)$.

Table 1. Effect of dietary sodium butyrate on the short-chain fatty acids concentration and $\mathrm{pH}$ of the proximal small intestinal digesta

\begin{tabular}{|c|c|c|c|c|}
\hline \multirow[b]{2}{*}{ Item } & \multicolumn{2}{|c|}{ Treatment $^{1}$} & \multirow[b]{2}{*}{ SEM $^{2}$} & \multirow[b]{2}{*}{$P$-value } \\
\hline & $\overline{\text { CTRL }}$ & $\overline{\text { BUT }}$ & & \\
\hline Total $\mathrm{SCFA}^{3}, \mathrm{mmol} / \mathrm{L}$ & 5.66 & 9.36 & 1.844 & 0.18 \\
\hline Acetate, $\mathrm{mmol} / \mathrm{L}$ & 4.81 & 7.61 & 1.473 & 0.20 \\
\hline Propionate, $\mathrm{mmol} / \mathrm{L}$ & 0.59 & 0.96 & 0.231 & 0.28 \\
\hline Butyrate, mmol/L & 0.22 & 0.68 & 0.143 & 0.05 \\
\hline Valerate, $\mathrm{mmol} / \mathrm{L}$ & 0.16 & 0.44 & 0.011 & 0.09 \\
\hline Isobutyrate, $\mathrm{mmol} / \mathrm{L}$ & 0.01 & 0.02 & 0.007 & 0.07 \\
\hline Isovalerate, $\mathrm{mmol} / \mathrm{L}$ & 0.03 & 0.04 & 0.009 & 0.45 \\
\hline Duodenum $\mathrm{pH}$ & 5.77 & 6.02 & 0.383 & 0.59 \\
\hline
\end{tabular}

${ }^{1}$ Sheep were fed diet without (CTRL) or with $36 \mathrm{~g}$ of sodium butyrate/kg of offered DM (BUT).

${ }^{2}$ Standard error of the mean.

${ }^{3}$ Short-chain fatty acids.
Aminopeptidase A and dipeptidylpeptidase IV activity in the distal jejunum and PepT1 mRNA expression in the distal jejunal and ileal epithelium were less for BUT compared with CTRL $(P \leq 0.05$; Table 5). GPR 43 mRNA expression in the duodenal epithelium was greater for BUT compared with CTRL $(P<0.01)$. No effect of exogenous butyrate on other investigated brush border enzymes and gene expression was observed (Supplementary Tables S2 and S3).

Amylolytic activity in the reticulorumen was greater, whereas cellulolytic and xylanolytic activity was less for BUT compared with CTRL $(P \leq 0.04$; Table 6).

\section{DISCUSSION}

Although it can be expected that ruminal butyrate predominantly affects the rumen, from 10 to $15 \%$ of ruminal SCFA was reported to flow with the digesta to the omasum, abomasum, and then the small intestine (Peters et al., 1990; López et al., 2003). In the current study, dietary butyrate increased butyrate concentration not only in the reticuloruminal digesta but also in the abomasal (data presented in the companion paper; Górka et al., 2018) and proximal small intestinal digesta,

Table 2. Effect of dietary sodium butyrate on the small intestine length and tissue mass

\begin{tabular}{lcccc}
\hline \hline & \multicolumn{2}{c}{ Treatment $^{1}$} & & \\
\cline { 2 - 3 } Item & CTRL & BUT & SEM $^{2}$ & $P$-value \\
\hline Entire small intestine & & & & \\
Length, cm & 1,884 & 2,077 & 60.4 & 0.04 \\
Mass, $g$ & 611 & 677 & 31.6 & 0.09 \\
Length, cm/kg BW & 58.6 & 62.2 & 2.84 & 0.15 \\
Mass, g/kg BW & 19.1 & 20.3 & 0.93 & 0.28 \\
Duodenum & & & & \\
Length, cm & 49.4 & 54.2 & 2.56 & 0.22 \\
Mass, g & 22.8 & 24.6 & 1.44 & 0.25 \\
Length, cm/kg BW & 1.54 & 1.63 & 0.086 & 0.39 \\
Mass, g/kg BW & 0.71 & 0.74 & 0.041 & 0.54 \\
Jejunum & & & & \\
Length, cm & 1,796 & 1,976 & 59.3 & 0.05 \\
Mass, g & 566 & 628 & 31.5 & 0.10 \\
Length, cm/kg BW & 55.9 & 59.2 & 2.72 & 0.19 \\
Mass, g/kg BW & 17.6 & 18.8 & 0.93 & 0.30 \\
Ileum & & & & \\
Length, cm & 38.8 & 46.8 & 4.99 & 0.16 \\
Mass, g & 23.0 & 25.4 & 2.08 & 0.33 \\
Length, cm/kg BW & 1.20 & 1.39 & 0.169 & 0.28 \\
Mass, g/kg BW & 0.71 & 0.76 & 0.066 & 0.52 \\
\hline
\end{tabular}

${ }^{1}$ Sheep were fed diet without (CTRL) or with $36 \mathrm{~g}$ of sodium butyrate $/ \mathrm{kg}$ of offered DM (BUT).

${ }^{2}$ Standard error of the mean. 
Table 3. Effect of dietary sodium butyrate on the small intestine structure

\begin{tabular}{|c|c|c|c|c|}
\hline \multirow[b]{2}{*}{ Item } & \multicolumn{2}{|c|}{ Treatment $^{1}$} & \multirow[b]{2}{*}{ SEM $^{2}$} & \multirow[b]{2}{*}{$P$-value } \\
\hline & CTRL & BUT & & \\
\hline \multicolumn{5}{|l|}{ Duodenum } \\
\hline Villus length, $\mu \mathrm{m}$ & 607 & 615 & 30.8 & 0.85 \\
\hline Crypt depth, $\mu \mathrm{m}$ & 195 & 214 & 7.6 & 0.10 \\
\hline Mucosa thickness, $\mu \mathrm{m}$ & 812 & 837 & 30.8 & 0.57 \\
\hline Muscularis thickness, $\mu \mathrm{m}$ & 127 & 118 & 11.5 & 0.54 \\
\hline \multicolumn{5}{|l|}{ Proximal jejunum } \\
\hline Villus length, $\mu \mathrm{m}$ & 399 & 441 & 20.2 & 0.13 \\
\hline Crypt depth, $\mu \mathrm{m}$ & 209 & 208 & 9.6 & 0.99 \\
\hline Mucosa thickness, $\mu \mathrm{m}$ & 609 & 651 & 25.8 & 0.21 \\
\hline Muscularis thickness, $\mu \mathrm{m}$ & 77 & 77 & 6.9 & 0.93 \\
\hline \multicolumn{5}{|l|}{ Middle jejunum } \\
\hline Villus length, $\mu \mathrm{m}$ & 469 & 469 & 35.6 & 1.00 \\
\hline Crypt depth, $\mu \mathrm{m}$ & 272 & 277 & 13.7 & 0.82 \\
\hline Mucosa thickness, $\mu \mathrm{m}$ & 742 & 747 & 42.5 & 0.93 \\
\hline Muscularis thickness, $\mu \mathrm{m}$ & 81 & 82 & 6.1 & 0.82 \\
\hline \multicolumn{5}{|l|}{ Distal jejunum } \\
\hline Villus length, $\mu \mathrm{m}$ & 435 & 433 & 22.2 & 0.95 \\
\hline Crypt depth, $\mu \mathrm{m}$ & 251 & 243 & 11.7 & 0.64 \\
\hline Mucosa thickness, $\mu \mathrm{m}$ & 687 & 677 & 32.6 & 0.83 \\
\hline Muscularis thickness, $\mu \mathrm{m}$ & 80 & 84 & 3.6 & 0.36 \\
\hline \multicolumn{5}{|l|}{ Ileum } \\
\hline Villus length, $\mu \mathrm{m}$ & 463 & 446 & 13.9 & 0.38 \\
\hline Crypt depth, $\mu \mathrm{m}$ & 263 & 241 & 9.2 & 0.10 \\
\hline Mucosa thickness, $\mu \mathrm{m}$ & 726 & 688 & 18.7 & 0.13 \\
\hline Muscularis thickness, $\mu \mathrm{m}$ & 171 & 144 & 13.4 & 0.10 \\
\hline
\end{tabular}

${ }^{1}$ Sheep were fed diet without (CTRL) or with $36 \mathrm{~g}$ of sodium butyrate $/ \mathrm{kg}$ of offered DM (BUT).

${ }^{2}$ Standard error of the mean.

Table 4. Effect of dietary sodium butyrate on the mitotic and apoptotic indices in the proximal jejunum and ileum

\begin{tabular}{lcccc}
\hline \hline & \multicolumn{2}{c}{ Treatment $^{1}$} & & \\
\cline { 2 - 3 } Item & CTRL & BUT & SEM $^{2}$ & $P$-value \\
\hline Proximal jejunum & & & & \\
$\quad$ Mitotic index, \% & 5.73 & 4.54 & 0.584 & 0.18 \\
$\quad$ Apoptotic index, \% & 5.99 & 7.92 & 1.095 & 0.10 \\
$\quad$ Mitosis-to-apoptosis ratio & 1.16 & 0.62 & 0.207 & 0.02 \\
Ileum & & & & \\
$\quad$ Mitotic index, \% & 6.48 & 5.60 & 1.326 & 0.41 \\
$\quad$ Apoptotic index, \% & 9.14 & 8.15 & 0.714 & 0.20 \\
$\quad$ Mitosis-to-apoptosis ratio & 0.73 & 0.73 & 0.113 & 1.00 \\
\hline
\end{tabular}

${ }^{1}$ Sheep were fed diet without (CTRL) or with $36 \mathrm{~g}$ of sodium butyrate/kg of offered DM (BUT).

${ }^{2}$ Standard error of the mean.

providing evidence that butyrate flow to the lower regions of the GIT depends on butyrate availability in the reticulorumen. In the companion paper, exogenous butyrate supplementation and the resulting greater butyrate flow out of the reticulorumen was associated with changes in the structure and functions of the omasum and abomasum (Górka et al., 2018). In this paper, the effect of exogenous butyrate on the small intestine structure and the selected functions, and also the activity of carbohydrate-digesting enzymes in the reticuloruminal digesta of sheep, is presented.

Although the main aim of this study was to determine the effect of exogenous butyrate on the small intestine structure and functions, its impact on carbohydrate-digesting enzymes activity in the reticuloruminal digesta was also investigated. Exogenous butyrate was shown to affect the ecosystem of rumen microbes in cattle and nutrient digestion in the stomach of sheep ( $\mathrm{Li}$ et al., 2012; Górka et al., 2017b). Therefore, the effect of butyrate on nutrient digestibility in the reticulorumen and associate changes in the composition of the digesta entering the intestine may have had an even greater impact on the intestine functions than the butyrate inflow itself. Specifically, the results of the present study suggest a negative impact of butyrate on microbes involved in the fiber degradation, but a stimulatory impact on the starch fermenting ones. Lower cellulolytic and xylanolytic activity in the reticuloruminal digesta of BUT animals is in line with earlier results (Górka et al., 2017 b), showing a negative impact of butyrate infusion (over $12 \mathrm{~d} ; 30 \mathrm{~g}$ of butyrate/kg of DMI) into the rumen on fiber digestion in the stomach of sheep (e.g., reticulorumen, omasum, and abomasum). Simultaneously, butyrate infusion into the reticulorumen of sheep had no effect on total tract nutrient digestibility (Agarwal et al., 2015; Górka et al., 2017b), indicating that less efficient fiber digestion due to increased ruminal butyrate in the forestomach can be compansated for by more efficient fiber digestion in the intestine-at least in sheep. Therefore, the shift of fiber digestion from the forestomach to the intestine, as well as more intense starch fermentation in the reticulorumen and the associated lower amount of starch entering the intestine (due to greater amylolytic acitivity in the reticulorumen of the BUT animals), might have affected the structure and function of the intestine and should be taken into account when interpreting the data from the present study.

Both butyrate infusion into the rumen and promotion of its ruminal production (by increased sugar content in the diet) resulted in greater apparent total-tract OM digestibility in cattle (Huhtanen et al., 1993; Chibisa et al., 2015). The aforementioned impact of promotion of ruminal butyrate 
production on nutrient digestion in cattle could be at least partially associated with greater butyrate flow to the duodenum and its effect on the structure and function of the small intestine. In monogastric animals and preruminants, butyrate supplementation led to greater villus length, crypt depth, and greater brush border enzymes activity (Gálfi and Bokori, 1990; Kotunia et al., 2004; Guilloteau et al., 2009; Górka et al., 2014). This effect was observed when butyrate was supplemented at a very low level $(\approx 0.2$ to $0.3 \%$ of DM). Furthermore, the impact on the entire small intestine was observed despite rapid butyrate absorption and utilization by proximal regions of the GIT when the level of its supplementation is low, as indicated by undetectable butyrate concentration in the digesta of the stomach and duodenum (Gálfi and Bokori, 1990; Manzanilla et al., 2006; Guilloteau et al., 2009). As a result, not only a direct but also an indirect mode of butyrate action on the small intestine was postulated, particularly in relation to the impact on the structure and functions of the middle and distal small intestine (Frankel et al., 1994; Guilloteau et al., 2009; Guilloteau et al., 2010a). In the present study, the dose of the dietary butyrate $(\approx 25 \mathrm{~g} / \mathrm{d}$ or $285 \mathrm{mmol} / \mathrm{d}$ ) could potentially double the butyrate production in the rumen of sheep (Bergman et al., 1965; Bergman, 1990) and tripled butyrate concentration in the proximal small intestinal digesta. This substantial increase in butyrate concentration in the duodenum was associated with greater expression of GPR43 in the duodenal epithelium, indicating a direct impact of butyrate flowing out of the rumen. All SCFA found in the largest concentration in the digesta of the GIT (acetate, propionate, and butyrate) can activate GPR 43, although with different potential (Brown et al., 2003; Le Poul et al., 2003). In contrast, when butyrate was infused into the rumen, no effect on GPR41 and GPR43 mRNA levels in the duodenal epithelium were shown (Górka et al., 2017b). However, in the study of Górka et al. (2017b), butyrate was infused into the rumen continuously, which resulted in a much lower butyrate increase in the reticuloruminal and duodenal digesta (and likely less variable over a day) than in the present study. On the other hand, Foote et al. (2017) showed changes in the mRNA expression of genes involved in the mitochondrial function, glycolysis, and fatty acid metabolism in the duodenal epithelium as a response to abomasal infusion of butyrate. At least part of this response could be due to the direct impact of butyrate escaping absorption in the abomasum and flowing to the intestine.
Besides greater expression of GPR43 mRNA in the duodenal epithelium of the BUT animals, the direct effect of butyrate entering the intestine may be confirmed by lower mitosis-to-apoptosis ratio in the epithelium of the proximal jejunum. Taking into account the mostly stimulatory effect of butyrate on GIT epithelial cell proliferation reported to date in in vivo studies (Guilloteau et al., 2009; Górka et al., 2011b), lower mitosis-to-apoptosis index in the duodenal epithelium should be interpreted as a consequence of enhanced proliferation several days earlier. Enhanced proliferation must be followed sooner or later by enhanced cell apoptosis. For example, butyrate infusion into the rumen, as well as dietary changes leading to greater SCFA production in the rumen, were shown to increase ruminal epithelial cell proliferation for $5 \mathrm{~d}$ after initiation of the experimental protocols (Sakata and Tamate, 1978; Goodlad, 1981). After day 5 the proliferation rate of the epithelium decreased (Sakata and Tamate, 1978). It is also worth mentioning that although low concentrations of butyrate stimulate intestinal epithelial cell proliferation, high concentrations have a suppressive impact and may induce apoptosis (Inagaki and Sakata, 2005; Peng et al., 2007). Taking into account the fact that the experimental model used in the present study resulted in very high butyrate concentration in the duodenal digesta (as compared to the control), it cannot be excluded that excessive exposure to butyrate might induce apoptosis of normal intestinal epithelial cells in vivo, as confirmed by the tendency to a greater apoptosis index in the proximal small intestinal epithelium for the BUT animals. Similarly, in the companion study, exogenous butyrate decreased mitosis-to-apoptosis ratio in the epithelium of the abomasum (Górka et al., 2018).

As previously mentioned, besides the direct effect on the small intestine structure and functions, the indirect effect of butyrate has been postulated. This effect might have been mediated by the impact of butyrate on the secretion of GIT peptides and hormones or a vagal nerve stimulation (Frankel et al., 1994; Guilloteau et al., 2009; Guilloteau et al., 2010a). Although in the present study butyrate concentration in the digesta of the middle and distal small intestine (ileum) was not determined, dietary butyrate was unlikely to affect butyrate concentration in those far regions of the GIT due to its rapid absorption and utilization by the epithelium of the stomach and proximal small intestine (Gálfi and Bokori, 1990; Manzanilla et al., 2006; Guilloteau et al., 2009). Therefore, the impact on the distal sections of the small intestine could be attributed to the 
Table 5. Effect of dietary sodium butyrate on the aminopeptidase A and dipeptidylpeptidase IV activity $\left(\mathrm{U} \times 10^{-3} / \mathrm{mg}\right.$ protein $)$, and peptide transporter 1 (PepT1) and G-protein-coupled receptor 43 (GPR43) mRNA expression in the small intestine epithelium

\begin{tabular}{|c|c|c|c|c|}
\hline \multirow[b]{2}{*}{ Item } & \multicolumn{2}{|c|}{ Treatment $^{1}$} & \multirow[b]{2}{*}{ SEM $^{2}$} & \multirow[b]{2}{*}{$P$-value } \\
\hline & CTRL & $\overline{\text { BUT }}$ & & \\
\hline \multicolumn{5}{|c|}{ Brush border enzyme activity } \\
\hline \multicolumn{5}{|l|}{ Aminopeptidase A } \\
\hline Duodenum & 3.0 & 2.8 & 0.38 & 0.72 \\
\hline Proximal jejunum & 19.5 & 23.6 & 2.86 & 0.24 \\
\hline Middle jejunum & 34.2 & 33.0 & 3.72 & 0.73 \\
\hline Distal jejunum & 44.6 & 30.8 & 5.57 & 0.05 \\
\hline Ileum & 43.4 & 43.7 & 7.05 & 0.98 \\
\hline \multicolumn{5}{|c|}{ Dipeptidylpeptidase IV } \\
\hline Duodenum & $\mathrm{nd}^{4}$ & nd & - & - \\
\hline Proximal jejunum & 11.5 & 12.5 & 1.16 & 0.56 \\
\hline Middle jejunum & 16.1 & 13.3 & 1.76 & 0.12 \\
\hline Distal jejunum & 20.5 & 14.5 & 1.91 & 0.01 \\
\hline Ileum & 22.7 & 21.3 & 2.63 & 0.65 \\
\hline \multicolumn{5}{|l|}{ mRNA expression ${ }^{3}$} \\
\hline \multicolumn{5}{|l|}{ PEPT1 } \\
\hline Duodenum & 3.02 & 4.60 & 1.427 & 0.41 \\
\hline Proximal jejunum & 3.19 & 4.09 & 1.772 & 0.64 \\
\hline Middle jejunum & 4.82 & 6.32 & 1.089 & 0.35 \\
\hline Distal jejunum & 2.93 & 4.69 & 0.784 & $<0.01$ \\
\hline Ileum & 1.51 & 3.60 & 0.933 & 0.04 \\
\hline \multicolumn{5}{|l|}{ GPR43 } \\
\hline Duodenum & 7.78 & 5.61 & 1.011 & 0.03 \\
\hline Proximal jejunum & 8.45 & 7.47 & 0.489 & 0.16 \\
\hline Middle jejunum & 10.7 & 10.1 & 0.75 & 0.59 \\
\hline Distal jejunum & 6.16 & 6.95 & 0.448 & 0.23 \\
\hline Ileum & 8.25 & 8.06 & 0.994 & 0.89 \\
\hline
\end{tabular}

${ }^{1}$ Sheep were fed diet without (CTRL) or with $36 \mathrm{~g}$ of sodium butyrate $/ \mathrm{kg}$ of offered DM (BUT).

${ }^{2}$ Standard error of the mean.

${ }^{3} \mathrm{Gene}$ expression is presented as relative gene expression $\left(\Delta \mathrm{C}_{\mathrm{T}}\right)$, where $\Delta \mathrm{C}_{\mathrm{T}}=$ threshold cycle $\left(\mathrm{C}_{\mathrm{T}}\right)$ for target gene $-\mathrm{C}_{\mathrm{T}}$ for reference; $\mathrm{a}$ higher $\Delta \mathrm{C}_{\mathrm{T}}$ value represents lower mRNA expression and vice versa.

${ }^{4}$ Where nd $=$ not detected.

indirect mode of butyrate action. However, besides a tendency to lower crypt depth and thinner muscularis in the ileum, no apparent effect of exogenous butyrate on the distal small intestine was found. On the other hand, however, overall intestinal length and tissue mass (and BW of animals; Górka et al., 2018) was increased. Since intraruminal butyrate infusion was shown to increase the plasma glucagon-like peptide-2 (GLP-2) concentration in sheep (Elsabagh et al., 2017), and GLP-2 is known to stimulate intestinal tissue growth in monogastrics, preruminants, and ruminants (Burrin et al., 2003; Górka et al., 2011a; Taylor-Edwards et al., 2011), greater intestinal length and tissue mass for the BUT animals
Table 6. Effect of dietary sodium butyrate supplementation on the carbohydrate-digesting enzymes activity in the reticulorumen digesta of sheep (U/g of digesta DM)

\begin{tabular}{|c|c|c|c|c|}
\hline \multirow[b]{2}{*}{ Item } & \multicolumn{2}{|c|}{ Treatment $^{1}$} & \multirow[b]{2}{*}{ SEM $^{2}$} & \multirow[b]{2}{*}{$P$-value } \\
\hline & CTRL & BUT & & \\
\hline Amylolytic activity & 14.9 & 17.7 & 0.90 & 0.04 \\
\hline Cellulolytic activity & 10.5 & 8.4 & 0.70 & 0.02 \\
\hline Xylanolytic activity & 26.1 & 17.3 & 1.87 & $<0.01$ \\
\hline Inulinolytic activity & 4.95 & 5.19 & 0.304 & 0.45 \\
\hline Pectinolytic activity & 6.36 & 6.53 & 0.367 & 0.61 \\
\hline
\end{tabular}

${ }^{1}$ Sheep were fed diet without (CTRL) or with $36 \mathrm{~g}$ of sodium butyrate/kg of offered DM (BUT)

${ }^{2}$ Standard error of the mean.

could be attributed to greater GLP-2 concentration in the blood. Alternatively, in herbivores, a relatively long small intestine (as compared to body length) was a result of evolutinary adapation to a feed high in fiber and of low digestibility (Van Soest, 1994). In the present study, exogenous butyrate reduced cellulolytic and xylanolytic activity, which likely contributed to lower fiber digestion in the forestomach (Górka et al., 2017b). Thus, greater intestinal length in the BUT animals could be at least partially a result of the adapation of the GIT necessary to assure efficient nutient utilization when the amount of fiber entering the intestine was increased.

Previous studies on mogastrics and preruminants showed a stimulatory impact of butyrate on brush border enzymes activity (Guilloteau et al., 2009; Górka et al., 2014) and a similar effect was expected in the present study. Contrary to this assumption, exogenous butyrate decreased aminopeptidase A and dipeptidylpeptidase IV activity and PepT1 mRNA expression in the distal small intestine, which may indicate a less intensive process of the protein digestion and absorption of products of this digestion in this section of the GIT. Butyrate stimulated PepT1 expression in vitro (Dalmasso et al., 2008). Taking into account that PepT1 expression as well as aminopeptidase A and dipeptidylpeptidase IV activities were the greatest in the distal small intestine, the direct impact of butyrate flowing out of the reticulorumen on this section of the intestine was unlikely due to earlier butyrate utilization (Gálfi and Bokori, 1990; Manzanilla et al., 2006; Guilloteau et al., 2009). Besides affecting brush border enzymes, butyrate was shown to increase pancreatic secretion in calves (Guilloteau et al., 2010b). If true also for the present study, this could have contributed to the more efficient digestion and absorption of nutrients in the proximal and middle jejunum. This, in turn, could result in less 
digesta and protein flowing to the distal section of the small intestine, as also supported by a tendency to the narrower crypts and thinner muscularis in the ileum reported in the present study.

Besides the impact on PepT1 mRNA expression, and thus protein absorption, no impact on the expression of other nutrient transporters has been found. Although gene expression at the mRNA level should be interpreted with caution - as it may not reflect protein expression or its functionality-mRNA expressions of SGLT1, GLUT2, PepT1, MCT1, MCT2, and MCT4 in the intestinal epithelium were used in the current study as markers of direct (proximal intestine) and indirect (distal intestine) impact of butyrate outflow from the reticulorumen on the functions of the small intestine. In accordance with these results, a similar dose of exogenous butyrate used in our earlier study did not affect MCT1, MCT2, and MCT4 expression in the duodenal epithelium, nutrient digestion in the intestine, as well as digestibility in the total digestive tract in sheep (Górka et al., 2017b). Alternatively, the stimulatory impact of butyrate on the function of the small intestine could occur shortly after the butyrate supplementation was initiated, e.g., prior to initiation of structural adaptation (changes of intestinal epithelium mass and intestine length).

In summary, the results of the present study showed that exogenous butyrate affected not only the rumen but also the small intestine. Greater GPR43 mRNA expression and less mitosis-to-apoptosis index of the proximal small intestinal epithelium indicated the direct impact of increased butyrate flow out of the reticulorumen on the proximal small intestinal epithelium. Furthermore, a longer small intestine, lower activity of aminopeptidase A and dipeptidylpeptidase IV, and lower mRNA expression of PepT1 in the distal jejunum and ileum was shown, indicating most likely the indirect impact of increased ruminal butyrate also on the distal sections of the small intestine.

\section{SUPPLEMENTARY DATA}

Supplementary data are available at Journal of Animal Science online.

\section{LITERATURE CITED}

Agarwal, U., Q. Hu, R. L. Baldwin, and B. J. Bequette. 2015. Role of rumen butyrate in regulation of nitrogen utilization and urea nitrogen kinetics in growing sheep. J. Anim. Sci. 93:2382-2390. doi:10.2527/jas.2014-8738

Andersen, C. L., J. L. Jensen, and T. F. Ørntoft. 2004. Normalization of real-time quantitative reverse transcription-PCR data: a model-based variance estimation approach to identify genes suited for normalization, applied to bladder and colon cancer data sets. Cancer Res. 64:5245-5250. doi:10.1158/0008-5472.CAN-04-0496

Bergman, E. N. 1990. Energy contributions of volatile fatty acids from the gastrointestinal tract in various species. Physiol. Rev. 70:567-590. doi:10.1152/physrev.1990.70.2.567

Bergman, E. N., R. S. Reid, M. G. Murray, J. M. Brockway, and F. G. Whitelaw. 1965. Interconversions and production of volatile fatty acids in the sheep rumen. Biochem. J. 97:53-58.

Brown, A. J., S. M. Goldsworthy, A. A. Barnes, M. M. Eilert, L. Tcheang, D. Daniels, A. I. Muir, M. J. Wigglesworth, I. Kinghorn, N. J. Fraser, et al. 2003. The orphan G protein-coupled receptors GPR41 and GPR43 are activated by propionate and other short chain carboxylic acids. J. Biol. Chem. 278:11312-11319. doi:10.1074/jbc. M211609200

Burrin, D. G., B. Stoll, and X. Guan. 2003. Glucagonlike peptide 2 function in domestic animals. Domest. Anim. Endocrinol. 24:103-122. doi:10.1016/ S0739-7240(02)00210

Chibisa, G. E., P. Gorka, G. B. Penner, R. Berthiaume, and T. Mutsvangwa. 2015. Effects of partial replacement of dietary starch from barley or corn with lactose on ruminal function, short-chain fatty acid absorption, nitrogen utilization, and production performance of dairy cows. J. Dairy Sci. 98:2627-2640. doi:10.3168/ jds.2014-8827

Chomczyński, P., and N. Sacchi. 1987. Single-step method of RNA isolation by acid guanidinium thiocyanate-phenol-chloroform extraction. Annal. Biochem. 162:156-159. doi:10.1006/abio.1987.9999

Dahlqvist, A. 1984. Assay of intestinal disaccharidases. Scand. J. Clin. Lab. Invest. 44:169-172. doi:10.3109/00365518409161400

Dalmasso, G., H. T. Nguyen, Y. Yan, L. Charrier-Hisamuddin, S. V. Sitaraman, and D. Merlin. 2008. Butyrate transcriptionally enhances peptide transporter PepT1 expression and activity. Plos One. 3:e2476. doi:10.1371/journal. pone. 0002476

DeFrain, J. M., A. R. Hippen, K. F. Kalscheur, and D. J. Schingoethe. 2004. Feeding lactose increases ruminal butyrate and plasma $\beta$-hydroxybutyrate in lactating dairy cows. J. Dairy Sci. 87:2486-2494. doi:10.3168/jds. S0022-0302(04)73373-1

Dengler, F., R. Rackwitz, F. Benesch, H. Pfannkuche, and G. Gäbel. 2014. Both butyrate incubation and hypoxia upregulate genes involved in the ruminal transport of SCFA and their metabolites. J. Anim. Physiol. Anim. Nutr. 90:379-390. doi:10.1111/jpn.12201

Elsabagh, M., Y. Inabu, T. Obitsu, and T. Sugino. 2017. Response of plasma glucagon-like peptide-2 to feeding pattern and intraruminal administration of volatile fatty acids in sheep. Domest. Anim. Endocrinol. 60:31-41. doi:10.1016/j.domaniend.2017.03.001

Foote, A. P., C. M. Zarek, L. A. Kuehn, H. C. Cunningham, K. M. Cammack, H. C. Freetly, and A. K. LindholmPerry. 2017. Effect of abomasal butyrate infusion on gene expression in the duodenum of lambs. J. Anim. Sci. 95:1191-1196. doi:10.2527/jas2016.1022

Frankel, W. L., W. Zhang, A. Singh, D. M. Klurfeld, S. Don, T. Sakata, I. Modlin, and J. L. Rombeau. 1994. Mediation of the trophic effects of short-chain fatty acids on the rat jejunum and colon. Gastroenterology. 106:375-380. doi:10.1016/0016-5085(94)90595-9 
Gálfi, P., and J. Bokori. 1990. Feeding trial in pigs with a diet containing sodium n-butyrate. Acta Vet. Hung. 38:3-17.

Godlewski, M. M., J. B. Bierla, A. Strzałkowski, D. MartinezPuig, B. Pajak, A. Kotunia, C. Chetrit, and R. Zabielski. 2009. A novel cytometric approach to study intestinal mucosa rebuilding in weaned pigs fed with dietary nucleotides. Lives. Sci. 123:215-220. doi:10.1016/j. livsci.2008.11.012

Goodlad, R. A. 1981. Some effects of diet on the mitotic index and the cell cycle of the ruminal epithelium of sheep. Q. J. Exp. Physiol. 66:487-499. doi:10.1113/expphysiol.1981. sp002590

Górka, P., Z. M. Kowalski, P. Pietrzak, A. Kotunia, W. Jagusiak, J. J. Holst, P. Guilloteau, and R. Zabielski. 2011a. Effect of method of delivery of sodium butyrate on rumen development in newborn calves. J. Dairy Sci. 94:5578-5588. doi:10.3168/jds.2011-4166

Górka, P., Z. M. Kowalski, P. Pietrzak, A. Kotunia, W. Jagusiak, and R. Zabielski. 2011b. Is rumen development in newborn calves affected by different liquid feeds and small intestine development? J. Dairy Sci. 94:30023013. doi:10.3168/jds.2010-3499

Górka, P., P. Pietrzak, A. Kotunia, R. Zabielski, and Z. M. Kowalski. 2014. Effect of method of delivery of sodium butyrate on maturation of the small intestine in newborn calves. J. Dairy Sci. 97:1026-1035. doi:10.3168/ jds.2013-7251

Górka, P., B. L. Schurmann, M. E. Walpole, A. Błońska, S. Li, J. C. Plaizier, Z. M. Kowalski, and G. B. Penner. 2017a. Effect of increasing the proportion of dietary concentrate on gastrointestinal tract measurements and brush border enzyme activity in holstein steers. J. Dairy Sci. 100:45394551. doi:10.3168/jds.2016-12162

Górka, P., B. Śliwiński, J. Flaga, J. Wieczorek, M. M. Godlewski, E. Wierzchoś, R. Zabielski, and Z. M. Kowalski. 2017b. Effect of butyrate infusion into the rumen on butyrate flow to the duodenum, selected gene expression in the duodenum epithelium, and nutrient digestion in sheep. $\mathbf{J}$. Anim. Sci. 95:2144-2155. doi:10.2527/jas.2016.1218

Górka, P., B. Śliwiński, J. Flaga, J. Olszewski, M. Wojciechowski, K. Krupa, M. M. Godlewski, R. Zabielski, and Z. M. Kowalski. 2018. Effect of exogenous butyrate on the gastrointestinal tract of sheep. I. Structure and function of the rumen, omasum, and abomasum. J. Anim. Sci. (in press).

Guilloteau, P., L. Martin, V. Eeckhaut, R. Ducatelle, R. Zabielski, and F. Van Immerseel. 2010a. From the gut to the peripheral tissues: the multiple effects of butyrate. Nutr. Res. Rev. 23:366-384. doi:10.1017/S0954422410000247

Guilloteau, P., G. Savary, Y. Jaguelin-Peyrault, V. Romé, L. Le Normand, and R. Zabielski. 2010b. Dietary sodium butyrate supplementation increases digestibility and pancreatic secretion in young milk-fed calves. J. Dairy Sci. 93:5842-5850. doi:10.3168/jds.2009-2751

Guilloteau, P., R. Zabielski, J. C. David, J. W. Blum, J. A. Morisset, M. Biernat, J. Wolinski, D. Laubitz, and Y. Hamon. 2009. Sodium-butyrate as a growth promoter in milk replacer formula for young calves. J. Dairy Sci. 92:1038-1049. doi:10.3168/jds.2008-1213

Hartree, E. F. 1972. Determination of protein: a modification of the Lowry method that gives a linear photometric response. Anal. Biochem. 48:422-427. doi:10.1016/0003-2697(72)90094-2
Huhtanen, P., H. Miettinen, and M. Ylinen. 1993. Effect of increasing ruminal butyrate on milk yield and blood constituents in dairy cows fed a grass silagebased diet. J. Dairy Sci. 76:1114-1124. doi:10.3168/jds. S0022-0302(93)77440-8

Inagaki, A., and T. Sakata. 2005. Dose-dependent stimulatory and inhibitory effects of luminal and serosal n-butyric acid on epithelial cell proliferation of pig distal colonic mucosa. J. Nutr. Sci. Vitaminol. (Tokyo). 51:156-160.

Kotunia, A., J. Woliński, D. Laubitz, M. Jurkowska, V. Romé, P. Guilloteau, and R. Zabielski. 2004. Effect of sodium butyrate on the small intestine development in neonatal piglets fed [correction of feed] by artificial sow. J. Physiol. Pharmacol. 55(Suppl 2):59-68.

Kowalski, Z. M., P. Górka, J. Flaga, A. Barteczko, K. Burakowska, J. Oprządek, and R. Zabielski. 2015. Effect of microencapsulated sodium butyrate in the close-up diet on performance of dairy cows in the early lactation period. J. Dairy Sci. 98:3284-3291. doi:10.3168/ jds.2014-8688

Le Poul, E., C. Loison, S. Struyf, J. Y. Springael, V. Lannoy, M. E. Decobecq, S. Brezillon, V. Dupriez, G. Vassart, J. Van Damme, et al. 2003. Functional characterization of human receptors for short chain fatty acids and their role in polymorphonuclear cell activation. J. Biol. Chem. 278:25481-25489. doi:10.1074/jbc.M301403200

Li, R. W., S. Wu, R. L. Baldwin, 6 ${ }^{\text {th }}$ W. Li, and C. Li. 2012. Perturbation dynamics of the rumen microbiota in response to exogenous butyrate. Plos One. 7:e29392. doi:10.1371/journal.pone.0029392

López, S., F. D. Hovell, J. Dijkstra, and J. France. 2003. Effects of volatile fatty acid supply on their absorption and on water kinetics in the rumen of sheep sustained by intragastric infusions. J. Anim. Sci. 81:2609-2616. doi:10.2527/2003.81102609x

Malhi, M., H. Gui, L. Yao, J. R. Aschenbach, G. Gäbel, and Z. Shen. 2013. Increased papillae growth and enhanced shortchain fatty acid absorption in the rumen of goats are associated with transient increases in cyclin D1 expression after ruminal butyrate infusion. J. Dairy Sci. 96:7603-7616. doi:10.3168/ jds.2013-6700

Manzanilla, E. G., M. Nofrarías, M. Anguita, M. Castillo, J. F. Perez, S. M. Martín-Orúe, C. Kamel, and J. Gasa. 2006. Effects of butyrate, avilamycin, and a plant extract combination on the intestinal equilibrium of early-weaned pigs. J. Anim. Sci. 84:2743-2751. doi:10.2527/jas.2005-509

Maroux, S., D. Louvard, and J. Baratti. 1973. The aminopeptidases from hog intestinal brush border. Biochim. Biophys. Acta. 321:282-295. doi:10.1016/0005-2744(73)90083-1

Miller, G. L., R. Blum, W. E. Glennon, and A. L. Burton. 1960. Measurement of carboxymethylcellulase activity. Anal. Biochem. 1:127-132. doi:10.1016/0003-2697(60)90004-X

Miltko, R., G. Bełżecki, B. Kowalik, and J. Skomiał. 2016. Presence of carbohydrate-digesting enzymes throughout the digestive tract of sheep. Turk. J. Vet. Anim. Sci. 40:271-277. doi:10.3906/vet-1507-70

Nagatsu, T., M. Hino, H. Fuyamada, H. Hayakawa, T. Sakakibara, Y. Nakagawa, and T. Takemoto. 1976. New chromogenic substrates for X-propyl dipeptidyl-aminopeptidase. Anal. Biochem. 74:466-476. doi:10.1016/0003-2697(76)90227-X

Peng, L., Z. He, W. Chen, I. R. Holzman, and J. Lin. 2007. Effects of butyrate on intestinal barrier function in a Caco- 2 cell monolayer model of intestinal barrier. Pediatr. Res. 61:37-41. doi:10.1203/01.pdr.0000250014.92242.f3 
Peters, J. P., R. Y. Shen, J. A. Robinson, and S. T. Chester. 1990. Disappearance and passage of propionic acid from the rumen of the beef steer. J. Anim. Sci. 68:3337-3349. doi:10.2527/1990.68103337x

Ploger, S., F. Stumpff, G. B. Penner, J. D. Schulzke, G. Gäbel, H. Martens, Z. M. Shen, D. Gunzel, and J. R. Aschenbach. 2012. Microbial butyrate and its role for barrier function in the gastrointestinal tract. In: M. Fromm and J. D. Schulzke, editors, Annals of the New York academy of sciences. Vol. 1258. Blackwell Science Publ., Oxford, UK. p. 52-59. doi:10.1111/j.1749-6632.2012.06553.x

Sakata, T., and H. Tamate. 1978. Rumen epithelial cell proliferation accelerated by rapid increase in intraruminal butyrate. J. Dairy Sci. 61:1109-1113. doi:10.3168/jds.S0022-0302(78)83694-7

Storm, A. C., M. D. Hanigan, and N. B. Kristensen. 2011. Effects of ruminal ammonia and butyrate concentrations on reticuloruminal epithelial blood flow and volatile fatty acid absorption kinetics under washed reticulorumen conditions in lactating dairy cows. J. Dairy Sci. 94:3980 3994. doi:10.3168/jds.2010-4091

Taylor-Edwards, C. C., D. G. Burrin, J. J. Holst, K. R. McLeod, and D. L. Harmon. 2011. Glucagon-like peptide-2 (GLP2) increases small intestinal blood flow and mucosal growth in ruminating calves. J. Dairy Sci. 94:888-898. doi:10.3168/jds.2010-3540

Van Soest, P. 1994. Nutritional ecology of the ruminant. 2nd ed. Cornell University Press, Ithaca.

Wiese, B. I., P. Górka, T. Mutsvangwa, E. Okine, and G. B. Penner. 2013. Short communication: Interrelationship between butyrate and glucose supply on butyrate and glucose oxidation by ruminal epithelial preparations. J. Dairy Sci. 96:5914-5918. doi:10.3168/jds.2013-6677

Wilson, D. J., T. Mutsvangwa, and G. B. Penner. 2012. Supplemental butyrate does not enhance the absorptive or barrier functions of the isolated ovine ruminal epithelia. J. Anim. Sci. 90:3153-3161. doi:10.2527/jas.2011-4315 